\title{
Acúmulo de matéria seca e nutrientes no meloeiro irrigado sob estratégias de manejo da salinidade ${ }^{1}$
}

\author{
Cícero P. C. Terceiro $\mathrm{Neto}^{2}$, José F. de $\mathrm{Medeiros}^{3}, \mathrm{H}$ ans R. G heyi ${ }^{4}$, \\ Nildo da S. Dias ${ }^{3}$, Francisco R. A. de O liveira $^{5} \&$ Keivianne da S. Lima ${ }^{6}$
}

\begin{abstract}
RESU M 0
0 presente estudo foi realizado com o objetivo de investigar estratégias de uso de água salobra sobre 0 acúmulo de matéria seca e nutrientes, duas cultivares de melão (Sancho - $C_{1}$ e Medellín - $C_{2}$ ) irrigadas com água de baixa $\left(\mathrm{S}_{1}=0,61 \mathrm{dS} \mathrm{m}^{-1}\right)$ e alta $\left(\mathrm{S}_{2}=4,78 \mathrm{dS} \mathrm{m}^{-1}\right)$ salinidade por fase da cultura: $\mathrm{S}_{1} \mathrm{~S}_{1} \mathrm{~S}_{2} \mathrm{~S}_{2}$ $\mathrm{T}_{1}, \mathrm{~S}_{2} \mathrm{~S}_{1} \mathrm{~S}_{2} \mathrm{~S}_{2}-\mathrm{T}_{2}, \mathrm{~S}_{2} \mathrm{~S}_{2} \mathrm{~S}_{1} \mathrm{~S}_{2}-\mathrm{T}_{3}$ (os $1,2,3$ e 4 o termos correspondem, respectivamente, às fases de crescimento, floração, crescimento dos frutos e maturação e colheita) e, ainda a irrigação alternada, durante todo o ciclo, com água $\mathrm{S}_{1}$ por 2 dias consecutivos seguido com água $\mathrm{S}_{2}$ por um dia $\left(\mathrm{S}_{1} 2\right.$ dias + $\mathrm{S}_{2}$ 1dia - $\mathrm{T}_{4}$ ) e a irrigação com água $\mathrm{S}_{2}$ durante todo o ciclo $-\mathrm{T}_{5}$. Além disto foi utilizada, como testemunha, a irrigação com a mistura de $37 \%$ da água $S_{1}$ e $63 \%$ da água $S_{2}-T_{0}$ (manejo adotado atualmente na fazenda em que 0 experimento foi conduzido). 0 delineamento experimental utilizado foi 0 de blocos inteiramente casualizados em um esquema de parcelas subdivididas $6 \times 2$ (manejo da água salina $x$ cultivar) com quatro repetições. 0 acúmulo de fitomassa seca total na parte aérea da cultivar Sancho foi superior ao de Medellín, em todas as estratégias de manejo utilizado; os nutrientes mais absorvidos pelas plantas das duas cultivares foram o cálcio, o potássio e o nitrogênio.
\end{abstract}

Palavras-chave: Cucumis melo L., estresse salino, nutrição de plantas

\section{Accumulation of dry matter and nutrients in irrigated melon under strategies of salimity management}

\begin{abstract}
A B STRACT
A study was carried out aiming to investigate management strategies for use of brackish water in the accumulation of dry matter and nutrients in two cultivars of melon $\left(C_{1}\right.$ - Sancho and $C_{2}-M$ edellin) irrigated

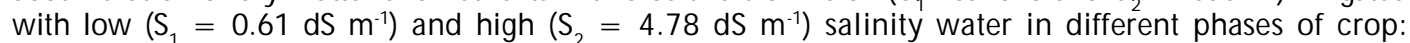
$\mathrm{S}_{1} \mathrm{~S}_{1} \mathrm{~S}_{2} \mathrm{~S}_{2}-\mathrm{T}_{1}, \mathrm{~S}_{2} \mathrm{~S}_{1} \mathrm{~S}_{2} \mathrm{~S}_{2}-\mathrm{T}_{2}, \mathrm{~S}_{2} \mathrm{~S}_{2} \mathrm{~S}_{1} \mathrm{~S}_{2}-\mathrm{T}_{3}$. The $1^{\text {st }}, 2^{\text {nd }}, 3^{\text {rd }}$ and $4^{\text {th }}$ term correspond, respectively, to different phases - initial growth, flowering, fruit maturation and harvest. Alternate irrigation during the crop cycle, two days of consecutive application with $S_{1}$ water followed by one day with $S_{2}$ water $\left(S_{1} 2\right.$ days $+S_{2}$ 1day - $T_{4}$ ) and irrigation with $S_{2}$ water throughout the cycle $-T_{5}$ was also tested. Furthermore, as control, management practice at the farm where the experiment was conducted consisting of irrigation with a mixture of $37 \% \mathrm{~S}_{1}$ water and $63 \%$ of $\mathrm{S}_{2}$ water $-\mathrm{T}_{0}$ was used. The experiment was conducted in a completely rando mized design in a $6 \times 2$ split-plots with four replications. The total dry matter accumulation in shoots of cv. Sancho was greater than Medellín in all management strategies. The nutrients required most by the two cultivars were calcium, potassium and nitrogen.
\end{abstract}

Key words: Cucumis melo L., salt stress, plant nutrient

${ }^{1}$ Parte da tese de doutorado do primeiro autor apresentada ao Programa de Pós-G raduação em Engenharia Agrícola da UFCG

2 EMATER, BR 230 - km 13, Estrada de Cabedelo, CEP 58310-000, Cabedelo, PB. Fone: (83) 3387-1099. E-mail: cicerocordao@yahoo.com.br 3 UFERSA, BR 110, km 47, Presidente Costa e Silva, CEP 59625-900, M ossoró, RN. Fone: (84) 3317-8340. E-mail: jfmedeir@ufersa.edu.br; nildo@ufersa.edu.br

${ }^{4}$ U FRB, C.P. 118, CEP 44380-000, Cruz das Almas, BA. Fone: (76) 3621-2798. E-mail: hans@agriambi.com.br

${ }_{5}^{5}$ Pós-graduando em Solos e Nutrição de Planta, U FC, Av. Mister Hull, 2977, Campus do Pici, Bloco 807, CEP 60440-554, Fortaleza, CE. Fone: (85) 3366-9688. E-mail: ronaldoindep@yahoo.com.br

${ }^{6}$ Graduanda do curso de Agronomia, UFERSA. E-mail: kei.v@hotmail.com 


\section{INTRODUÇÃO}

No semiárido brasileiro são grandes as potencialidades para a fruticultura irrigada, pelas peculiaridades, como temperaturas elevadas e luminosidade durante praticamente o ano inteiro. Dentre os cultivos se destaca o melão (Cucumis melo L.), responsável por cerca de $92 \%$ de toda a produção nacional (IBGE, 2010).

A produção de melão no Rio Grande do Norte se concentra na microrregião de Mossoró, onde parte da água utilizada para irrigação é proveniente de poços artesianos profundos que, apesar da boa qualidade, apresenta alto custo de obtenção o que, às vezes, inviabiliza seu uso na agricultura. Entretanto, há também poços perfurados no calcário Jandaíra que, embora apresentando custo de obtenção mais baixo, possui água com salinidade elevada. Nos cultivos irrigados desta região tem sido comum a substituição de água de boa qualidade por água salobra dos poços rasos, em razão do menor custo (Dias et al., 2010).

Uma alternativa para esta situação seria misturar águas de boa e de qualidade inferior e, assim, aumentar a disponibilidade hídrica para as culturas. Esta mistura pode permitir a irrigação de áreas maiores, mas não diminui o total dos sais, motivo pelo qual se tornam imprescindíveis investigações sobre o uso racional dessas águas, haja vista que sua utilização pode salinizar os solos e diminuir o rendimento dos cultivos (Soares et al., 2006; ; Dias et al., 2007; Aragão et al., 2009; Santos et al., 2010).

Apesar do crescente interesse pela exploração da cultura do meloeiro no semiárido nordestino, são poucas as investigações quanto aos aspectos de sua nutrição mineral. É imprescindível o conhecimento das exigências nutricionais da cultura, ao longo do ciclo, como referência para estabelecimento de programas de fertigação, possibilitando o fornecimento dos nutrientes em épocas e doses adequadas ao bom desenvolvimento vegetal. Em conjunto com o conhecimento da absorção de nutrientes, faz-se necessário investigar os efeitos da salinidade sobre a nutrição das plantas considerandose a predominância de água salobras nas áreas produtoras de melão no semiárido brasileiro tal como a estratégia de manejo utilizada pelos produtores, ou seja, de misturar águas de boa e de qualidade inferior.

$\mathrm{Na}$ cultura do meloeiro foram realizados alguns estudos (Silva Júnior et al., 2006; Gurgel et al., 2008; Dias et al., 2010) com acúmulo de nutrientes porém não foram encontrados registros sobre crescimento e estado nutricional de cultivares de melão sob diferentes práticas de manejo da água de irrigação com elevada concentração salina.

Assim, o objetivo do estudo foi avaliar o acúmulo de matéria seca e de nutrientes em plantas de duas cultivares de melão 'Pele de Sapo', irrigadas com água de baixa e alta salinidade, sob diferentes manejos.

\section{Material e MÉTOdos}

O experimento foi conduzido durante o período de 15 de setembro a 14 de novembro de 2009, em área da Fazenda Pedra Preta, pertencente ao grupo "CoopyFrutas", município de
Mossoró, RN (4 59’ 45,75" de latitude Sul e 37² 23' 11,82" de longitude a Oeste do meridiano de Greenwich e altitude média de $60 \mathrm{~m}$ ).

O solo da área experimental é um Argissolo VermelhoAmarelo com os seguintes atributos, obtidos em análises físicoquímicas, realizadas em amostras coletadas na camada 0-20 cm: 37,7 $\mathrm{g} \mathrm{kg}^{-1}$ de argila; $\mathrm{pH}_{\mathrm{es}}=7,08$; teores de $\mathrm{P}, \mathrm{Ca}^{2+}, \mathrm{Mg}^{2+}, \mathrm{K}^{+}$ e $\mathrm{Na}^{+}$iguais a 50,8 $\mathrm{mg} \mathrm{kg}^{-1}, 2,76,1,29,0,14$ e $0,15 \mathrm{cmol}_{\mathrm{c}} \mathrm{kg}^{-1}$, respectivamente, densidade global $=1,48 \mathrm{~kg} \mathrm{dm}^{-3}$, soma de bases $=4,34 \mathrm{cmol} \mathrm{kg}_{\mathrm{c}}^{-1}, \mathrm{CTC}=4,34 \mathrm{cmol}_{\mathrm{c}} \mathrm{kg}^{-1}$ determinados por metodologias da EMBRAPA (1997).

Os tratamentos consistiram da irrigação de duas cultivares de melão do grupo inodorus (cvs Sancho $-\mathrm{C}_{1}$ e Medellín $-\mathrm{C}_{2}$ ) em diferentes estratégias de uso de água de baixa $\left(S_{1}=0,61 \mathrm{dS}\right.$ $\left.\mathrm{m}^{-1}\right)$ e alta $\left(\mathrm{S}_{2}=4,78 \mathrm{dS} \mathrm{m^{-1 }}\right)$ concentração salina por cada fase fenológica da cultura: $\mathrm{S}_{1} \mathrm{~S}_{1} \mathrm{~S}_{2} \mathrm{~S}_{2}-\mathrm{T}_{1}, \mathrm{~S}_{2} \mathrm{~S}_{1} \mathrm{~S}_{2} \mathrm{~S}_{2}-\mathrm{T}_{2}, \mathrm{~S}_{2} \mathrm{~S}_{2} \mathrm{~S}_{1} \mathrm{~S}_{2}-\mathrm{T}_{3}$ (os $1^{\circ}, 2^{\circ}, 3^{\circ}$ e $4^{\circ}$ termos dessas sequências correspondem, respectivamente, às fases fenológicas de crescimento inicial, floração, enchimento de frutos e maturação dos frutos e colheita) e, ainda, a irrigação alternada, durante todo o ciclo, com água $\mathrm{S}_{2}$ por 2 dias consecutivo seguido com água $\mathrm{S}_{1}$ por um dia $\left(\mathrm{S}_{1}\right.$ 2dias $+\mathrm{S}_{2} 1$ dia $\left.-\mathrm{T}_{4}\right)$ e a irrigação com água $\mathrm{S}_{2}$ durante todo o ciclo $-\mathrm{T}_{5}$. Além disso foi utilizado, como testemunha, o manejo de irrigação com a mistura de $37 \%$ da água $\mathrm{S}_{1}$ e $63 \%$ da água $\mathrm{S}_{2}-\mathrm{T}_{0}$ (manejo atualmente adotado pela fazenda).

As fases de crescimento, floração, maturação dos frutos e colheita corresponderam, respectivamente, aos períodos compreendidos entre o transplantio até o aparecimento das flores femininas (12-30 dias após a semeadura-DAS), o aparecimento das flores femininas até início de formação de frutos (30-46 DAS), o início de formação de frutos até início da maturação (46-60 DAS) e deste até a colheita (60-75 DAS). A água utilizada na pesquisa foi proveniente dos aquíferos Arenito Açu, caracterizado por apresentar água de baixa salinidade $\left(0,61 \mathrm{dS} \mathrm{m}^{-1}\right)$ e do Calcário Jandaíra, de água salina $\left(4,78 \mathrm{dS} \mathrm{m}^{-1}\right)$.

As águas utilizadas na pesquisa provieram de dois aqüíferos: do aquífero Arenito Açu, com profundidade de aproximadamente $1000 \mathrm{~m}$, caracterizado por apresentar água de baixa salinidade e do Aquífero Calcário Jandaíra, este com profundidade em torno de $80 \mathrm{~m}$ com água salina. As características químicas dessas águas utilizadas nos experimentos se encontram na Tabela 1.

As análises químicas das águas de irrigação e fisico-químicas do solo, foram realizadas no Laboratório de Irrigação e Salinidade da Unidade Acadêmica de Engenharia Agrícola da

Tabela 1. Características químicas das águas utilizadas no experimento

\begin{tabular}{ccccc}
\hline Parâmetros & Unidades & $\begin{array}{c}\text { Poço } \\
\text { profundo }\left(\mathbf{S}_{1}\right)\end{array}$ & $\begin{array}{c}\text { Água de poço } \\
\text { raso }\left(\mathbf{S}_{2}\right)\end{array}$ & $\begin{array}{c}\text { Água misturada } \\
\left(\mathbf{S}_{\mathbf{0}}\right)^{*}\end{array}$ \\
$\mathrm{CE}_{\mathrm{a}}$ & $\mathrm{dS} \mathrm{m} \mathrm{m}^{-1}$ & 0,61 & 4,78 & 3,21 \\
$\mathrm{pH}$ & - & 6,67 & 6,40 & 6,75 \\
$\mathrm{~K}$ & $\mathrm{mmol}_{\mathrm{c}} \mathrm{L}^{-1}$ & 0,49 & 0,12 & 0,28 \\
$\mathrm{Na}$ & $\mathrm{mmol}_{\mathrm{c}} \mathrm{L}^{-1}$ & 2,46 & 22,06 & 13,78 \\
$\mathrm{Ca}$ & $\mathrm{mmol}_{\mathrm{c}} \mathrm{L}^{-1}$ & 1,91 & 14,70 & 9,98 \\
$\mathrm{Mg}$ & $\mathrm{mmol}_{\mathrm{c}} \mathrm{L}^{-1}$ & 1,46 & 6,17 & 5,34 \\
$\mathrm{CO}_{3}$ & $\mathrm{mmol}_{\mathrm{c}} \mathrm{L}^{-1}$ & 0,00 & 0,00 & 0,00 \\
$\mathrm{HCO}_{3}$ & $\mathrm{mmol}_{\mathrm{c}} \mathrm{L}^{-1}$ & 3,77 & 4,75 & 4,59 \\
$\mathrm{Cl}$ & $\mathrm{mmol}_{\mathrm{c}} \mathrm{L}^{-1}$ & 1,83 & 38,87 & 23,55 \\
$\mathrm{RAS}$ & $\left(\mathrm{mmol} \mathrm{L}^{-1}\right)^{0,5}$ & 1,89 & 6,82 & 4,97 \\
\hline Mistura contendo $37 \% \mathrm{~S}_{1} \mathrm{e} 63 \% \mathrm{~S}_{2}$ & \multicolumn{4}{l}{}
\end{tabular}


UFCG, segundo metodologia recomendada pela EMBRAPA (1997).

As cultivares estudadas se caracterizam por apresentarem frutos de casca mosqueada entre verde escuro e verde claro, levemente enrugada, de formato ovalado com polpa creme esverdeado, peso médio oscilando entre 1,8 a $2,5 \mathrm{~kg}$ e com potencial para exportação (Souza, 2006). Referidas cultivares foram escolhidas em razão de serem as mais exploradas pelos produtores e apresentarem área de cultivo em expansão na região, além da falta de informações técnicas, sobretudo quanto à tolerância a salinidade e por possuírem boa adaptação às condições climáticas da região e algumas características agronômicas, tais como tolerância a algumas doenças e pragas e excelente resistência pós-colheita.

$\mathrm{O}$ delineamento experimental utilizado foi o de blocos inteiramente casualizados em um esquema de parcelas subdivididas $6 \times 2$ com quatro repetições, totalizando 24 parcelas com $96 \mathrm{~m}^{2}(8,0 \times 12,0 \mathrm{~m})$ e 48 subparcelas com $48 \mathrm{~m}^{2}$ $(8,0 \times 6,0 \mathrm{~m})$; cada parcela foi composta de 4 fileiras espaçadas $2 \mathrm{~m}$ com $0,50 \mathrm{~m}$ entre plantas, equivalente a uma densidade de 10.000 plantas ha $^{-1}$.

O sistema de irrigação utilizado foi do tipo gotejamento, com gotejadores espaçados a $0,30 \mathrm{~m}$ com vazão de $1,30 \mathrm{Lh}^{-1}$ utilizandose dois sistemas de irrigação independentes, um para aplicar água de baixa salinidade e o outro para água salina. A irrigação foi realizada diariamente e a lâmina aplicada foi determinada a partir de estimativas da evapotranspiração da cultura calculada pela metodologia proposta pela FAO, utilizando-se o Kc estimado pelo Kc dual e evapotranspiração de referência segundo PenmanMonteith (ET $_{0}$ (Allen et al., 1998).

Visando à adubação de fundação foram fornecidos 420 $\mathrm{kg} \mathrm{ha}^{-1}$ da formulação N-P-K (6-24-12); já para a adubação de cobertura foi realizada via fertirrigação e aplicada a partir do quinto dia após o transplantio até o início da maturação; as quantidades $\left(\mathrm{kg} \mathrm{ha}^{-1}\right)$ de nutrientes aplicados durante o ciclo foram, 127; 176; 242; 8, 18; 1,26 e 1,2 de N, $\mathrm{P}_{2} \mathrm{O}_{5}, \mathrm{~K}_{2} \mathrm{O}, \mathrm{S}, \mathrm{B}$ e micronutrientes, respectivamente. Utilizaram-se, como fontes de $\mathrm{N}, \mathrm{P}$ e $\mathrm{K}$, os seguintes adubos: $\mathrm{KNO}_{3}$, ureia, ácido nítrico, $\mathrm{KCl}, \mathrm{K}_{2} \mathrm{SO}_{4}$, MAP, ácido fosfórico e, como fontes de micronutrientes, o ácido bórico e o quelatec AZ.

A semeadura foi realizada no dia 4 de setembro de 2009 em bandejas de polietileno com 200 células com substrato agrícola comercial; após 12 dias de semeio efetuou-se o transplantio das mudas para o local definitivo, através de uma planta por cova.

Foram realizadas, aos 28, 42, 56 e 69 DAS, medições de fitomassa seca de toda a parte aérea (FSPA), que incluem fitomassa seca dos ramos (caules + folhas) e frutos, além das determinação dos teores de N, P, K, Ca, Mg, Na, Fe, Cu, Zn e Mn nas folhas, caules e frutos em três tratamentos $\left(\mathrm{T}_{1}, \mathrm{~T}_{4} \mathrm{e} \mathrm{T}_{5}\right)$ nas duas cultivares estudadas; a partir dos teores desses nutrientes e da matéria seca de cada parte da planta determinouse, em cada fase de desenvolvimento da cultura, o conteúdo de nutrientes no caule, nas folhas, nos frutos e na parte aérea, obtendo-se as curvas de acúmulo de nutrientes ao longo do ciclo. As análises químicas para determinação dos teores de nutrientes foram realizadas no Laboratório de Irrigação e Salinidade da Universidade Federal de Campina Grande, PB, de acordo com a metodologia proposta pela EMBRAPA (1999).
Os dados de análise de fitomassa seca e os teores de nutrientes no tecido vegetal foram interpretados por meio de análise de variância, realizando-se a comparação de médias pelo teste de Tukey a 0,05 de probabilidade e se utilizando o programa estatístico Sisvar versão 4.3.

\section{RESULTADOS E DISCUSSÃO}

Verificou-se efeito significativo do fator estratégia de manejo da água de irrigação nas variáveis fitomassa seca da parte aérea (FSPA) apenas aos 28 DAS (Tabela 2), sendo a maior média de FSPA observada nas plantas do tratamento em que se aplicou água de baixa salinidade $\left(\mathrm{T}_{4}=24,95 \mathrm{~g}_{\text {planta }}{ }^{-1}\right)$ embora estatisticamente diferente apenas do $\mathrm{T}_{5}$ (água salina em todo ciclo).

Em relação ao fator cultivar, constatou-se efeito significativo aos 28, 56 e 69 DAS para a FSPA, com destaque para a cultivar Sancho, na qual se observam as maiores médias (Tabela 2). Porto Filho et al. (2006) constataram, em ensaios semelhantes utilizando-se outra cultivar, que os tratamentos nos quais se

Tabela 2. Valores médios* de fitomassa seca da parte aérea (FSPA), ramos (FSR) e frutos (FSF) das cultivares Sancho e M edellín, sob diferentes estratégias de manejo de água de irrigação aos 28, 42, 56 e 69 DAS

\begin{tabular}{|c|c|c|c|c|}
\hline \multirow{2}{*}{$\begin{array}{l}\text { Estratégia } \\
\text { de manejo }\end{array}$} & \multicolumn{4}{|c|}{ DAS } \\
\hline & 28 & 42 & 56 & 69 \\
\hline Tratamento & \multicolumn{4}{|c|}{ FSPA (g planta ${ }^{-1}$ ) } \\
\hline $\mathrm{T}_{1}$ & $23,72 a b$ & $122,26 \mathrm{a}$ & $404,88 a$ & $631,62 \mathrm{a}$ \\
\hline $\mathrm{T}_{2}$ & $18,46 a b$ & $134,14 \mathrm{a}$ & $342,54 a$ & $632,67 a$ \\
\hline $\mathrm{T}_{3}$ & $19,46 a b$ & 121,95 a & $304,34 a$ & $613,45 a$ \\
\hline $\mathrm{T}_{4}$ & $24,95 \mathrm{a}$ & $155,10 \mathrm{a}$ & $349,57 a$ & $723,85 a$ \\
\hline $\mathrm{T}_{5}$ & $16,58 b$ & 132,84 a & $344,05 a$ & $624,90 \mathrm{a}$ \\
\hline $\begin{array}{l}\mathrm{T}_{6} \\
\text { Cultivar }\end{array}$ & $20,34 a b$ & $122,21 \mathrm{a}$ & 393,51 a & $579,95 a$ \\
\hline Sancho & $22,36 a$ & 133,46 a & $385,46 a$ & $683,90 a$ \\
\hline Medellín & $18,81 \mathrm{~b}$ & 129,37 a & $327,50 \mathrm{~b}$ & $584,91 \mathrm{~b}$ \\
\hline Tratamento & \multicolumn{4}{|c|}{ FSR (g planta $\left.{ }^{-1}\right)$} \\
\hline $\mathrm{T}_{1}$ & $23,72 a b$ & $112,10 \mathrm{a}$ & $178,18 \mathrm{a}$ & $173,54 a$ \\
\hline $\mathrm{T}_{2}$ & $18,46 a b$ & 109,16 a & $146,77 \mathrm{a}$ & $173,12 \mathrm{a}$ \\
\hline $\mathrm{T}_{3}$ & $19,46 a b$ & $102,40 \mathrm{a}$ & $135,17 a$ & $147,76 \mathrm{a}$ \\
\hline $\mathrm{T}_{4}$ & $24,95 \mathrm{a}$ & $127,06 \mathrm{a}$ & $153,90 \mathrm{a}$ & $174,62 \mathrm{a}$ \\
\hline $\mathrm{T}_{5}$ & $16,58 b$ & $108,45 a$ & $153,95 a$ & $150,41 \mathrm{a}$ \\
\hline $\mathrm{T}_{6}$ & $20,34 a b$ & $103,34 a$ & $164,86 \mathrm{a}$ & $168,67 \mathrm{a}$ \\
\hline Cultivar & & & & \\
\hline Sancho & $22,36 a$ & $112,76 \mathrm{a}$ & $168,54 a$ & $189,08 \mathrm{a}$ \\
\hline Medellín & $18,81 \mathrm{~b}$ & $108,08 \mathrm{a}$ & $142,40 \mathrm{~b}$ & $140,29 \mathrm{~b}$ \\
\hline Tratamento & \multicolumn{4}{|c|}{ FSF (g planta ${ }^{-1}$ ) } \\
\hline $\mathrm{T}_{1}$ & - & $10,16 b$ & 226,69 a & $458,08 \mathrm{a}$ \\
\hline $\mathrm{T}_{2}$ & - & $24,96 a b$ & $195,76 a$ & $459,54 a$ \\
\hline $\mathrm{T}_{3}$ & - & $19,55 \mathrm{ab}$ & 169,17 a & $465,68 \mathrm{a}$ \\
\hline $\mathrm{T}_{4}$ & - & 28,04 a & 195,67 a & $549,22 \mathrm{a}$ \\
\hline $\mathrm{T}_{5}$ & - & $24,38 a b$ & $190,09 a$ & $474,49 a$ \\
\hline $\begin{array}{l}\mathrm{T}_{6} \\
\text { Cultivar }\end{array}$ & - & $18,87 \mathrm{ab}$ & 228,65 a & $411,28 a$ \\
\hline Sancho & - & $20,69 a$ & $216,91 \mathrm{a}$ & $494,82 \mathrm{a}$ \\
\hline Medellín & - & $21,29 a$ & $185,10 \mathrm{~b}$ & 444,61 a \\
\hline
\end{tabular}

$\mathrm{S}_{1}=0,61 \mathrm{dS} \mathrm{m} \mathrm{m}^{-1} \mathrm{e} \mathrm{S}_{2}=4,78 \mathrm{dS} \mathrm{m}^{-1} \cdot \mathrm{T}_{1}-\mathrm{S}_{1} \mathrm{~S}_{1} \mathrm{~S}_{2} \mathrm{~S}_{2}, \mathrm{~T}_{2}-\mathrm{S}_{2} \mathrm{~S}_{1} \mathrm{~S}_{2} \mathrm{~S}_{2} \mathrm{~S}_{2} \mathrm{~S}_{2} \mathrm{~S}_{1} \mathrm{~S}_{2}, \mathrm{~T}_{3}-\mathrm{S}_{1} 2$ dias $+\mathrm{S}_{2} 1 \mathrm{dia}$ $\mathrm{T}_{4}-\mathrm{S}_{1} 2$ dias $+\mathrm{S}_{2} 1$ dia, $\mathrm{T}_{5}$ - irrigação com água $\mathrm{S}_{2}$ durante todo 0 ciclo $\mathrm{e} \mathrm{T}_{0}$ - manejo de irrigação com a mistura de $37 \%$ da água $S_{1}$ e $63 \%$ da água $S_{2}$

Médias seguidas de letras diferentes na mesma coluna diferem entre si pelo teste de Tukey ( $P$ $<0,05$ ) 
variou o tipo de água a cada fase fenológica da cultura, não diferiram do uso inalterado dessas águas em todas as épocas avaliadas. Em referência ao acúmulo de fitomassa seca nos ramos (FSR), observa-se comportamento semelhante ao da FSPA para o fator estratégia de manejo; para as cultivares o efeito foi significativo aos 28, 56 e 69 DAS (Tabela 2); já no que se refere à fitomassa seca dos frutos, constata-se efeito significativo entre o fator estratégia de manejo aos 42 DAS e entre as cultivares aos 56 DAS observando-se, nos frutos, os maiores acúmulos de fitomassa seca representando, em média, $74 \%$ de toda a fitomassa seca acumulada (Tabela 2).

A partir do acúmulo de FSPA nota-se, ao longo das avaliações, crescimento lento da fase inicial até os 42 DAS em todos os tratamentos (Tabela 2) enquanto entre as cultivares se verifica que, em termos de acúmulo de FSPA, a cv. Sancho superou a Medellín em todas as épocas de avaliação, exceto aos 42 DAS, em que não ocorreu diferença significativa.

Em pesquisa realizada com as cultivares Goldex e Orange Flesh irrigadas com águas de baixa e alta salinidade, Gurgel et al. (2010a) também constataram crescimento lento até os 38 DAS, com posterior ganho de matéria seca até o final do ciclo, com maior intensidade nos frutos.

Os frutos foram os principais responsáveis pela maior concentração de FSPA nas duas cultivares e em todos os tratamentos; entretanto, referida superioridade dos frutos na cultivar Sancho foi mais acentuada no tratamento em que as plantas foram irrigadas com água $\mathrm{S}_{2}$ durante 2 dias consecutivos e com água $\mathrm{S}_{1}$ por um dia $\left(\mathrm{T}_{4}\right)$ atingindo $549,22 \mathrm{~g}_{\text {planta }}{ }^{-1}$ aos $69 \mathrm{DAS}$, correspondendo a aproximadamente $76 \%$ da fitomassa seca produzida; já entre as cultivares se constata um acúmulo maior de FSF na cultivar Sancho, mas apenas aos 56 DAS, não diferindo estatisticamente nas demais épocas de coleta (Tabela 2).

Para as duas cultivares, o acúmulo de $\mathrm{N}$ em todos os tratamentos foi crescente até a última avaliação (69 DAS) (Figura 1A a 1D), não havendo diferença significativa entre estratégias de manejo nesta data (Tabela 3); já com relação às cultivares tem-se diferença significativa entre elas, sendo o maior acúmulo de $\mathrm{N}$ na parte aérea observada na cultivar Sancho $(10,37 \mathrm{~g}$ planta $^{-1}$ ).

De maneira geral, em todas as estratégias de manejo e cultivares o maior acúmulo de nitrogênio foi observado nos frutos, seguidos de folhas e caule, sendo este acúmulo crescente até a última avaliação (Figura 1). Percebe-se ainda tendência de aumento no acúmulo de $\mathrm{N}$ nas folhas até os 56 DAS com posterior queda até os 69 DAS, em todas as estratégias de manejo e cultivares. A redução nos teores de nitrogênio se deve, provavelmente, ao efeito diluição desse nutriente na planta. Este efeito é caracterizado pela translocação do nutriente das folhas mais velhas para o fruto, o qual passa a se comportar como dreno (Taiz \& Zeiger, 2010).

Não ocorreu diferença significativa no conteúdo de nitrogênio nos frutos, seja em função dos tratamentos ou entre cultivares (Tabela 3), já a acumulação de nitrogênio em folhas e caule não foi influenciada pelos tratamentos, tendo apenas as folhas apresentado diferença significativa entre cultivares com médias de 3,88 e 2,50 g planta $^{-1}$ para as cultivares Sancho e Medellín, respectivamente (Tabela 3); tal diferença, associada
Sancho

A.

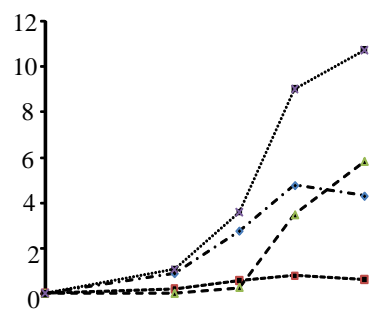

C.

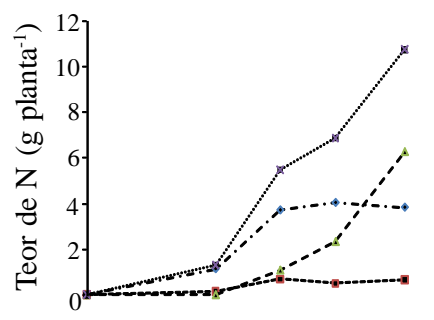

E

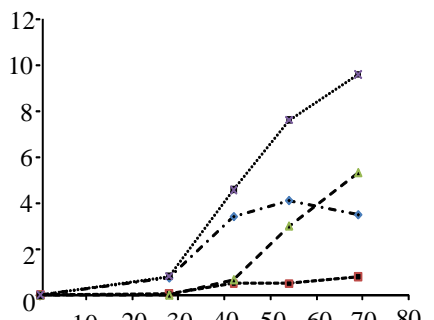

$\begin{array}{lllllllll}10 & 20 & 30 & 40 & 50 & 60 & 70 & 80\end{array}$

Dias após a semeadura

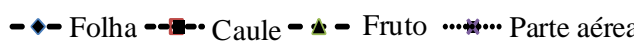

$\mathrm{S}_{1}=0,61 \mathrm{dS} \mathrm{m}^{-1} \mathrm{e} \mathrm{S}_{2}=4,78 \mathrm{dS}^{-1} \cdot \mathrm{T}_{1}-\mathrm{S}_{1} \mathrm{~S}_{1} \mathrm{~S}_{2} \mathrm{~S}_{2}, \mathrm{~T}_{4}-\mathrm{S}_{1} 2$ dias $+\mathrm{S}_{2} 1 \mathrm{dia} \mathrm{e} \mathrm{T}_{5}$ - irrigação com água $\mathrm{S}_{2}$ durante todo o ciclo

Figura 1. Acumulação de nitrogênio na parte aérea, folhas, caule e frutos em função dos dias após a semeadura para as cultivares Sancho e Medellín nos tratamentos com água boa - $T_{1}\left(A\right.$ e $B$ ) e $T_{4}\left(C\right.$ e $D$ ) e salina - $T_{5}(E$ e $F$ ) respectivamente

provavelmente às características genéticas das cultivares e não aos tratamentos estudados.

Os resultados obtidos no presente estudo para o acúmulo total de nitrogênio na fitomassa seca da parte aérea aos 69 DAS (Figura 1A a 1F), foram superiores aos obtidos por Gurgel et al. (2008) aos 63 DAS, em meloeiros submetidos aos níveis de salinidade de águas de 0,8 e 3,02 dS m ${ }^{-1}$; esses autores obtiveram, na cultivar Orange Flesh, 2,55 e 2,85 g planta ${ }^{-1}$ de nitrogênio na parte aérea quando irrigados com água de baixa e alta salinidade,

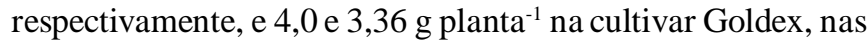
mesmas condições de salinidade, sendo os frutos os responsáveis por tal acúmulo, superiores também aos encontrados por Silva Júnior et al. (2006) que obtiveram, em média, aos 69 DAS, 3,40 g planta ${ }^{-1}$ na cultivar Sancho, sendo que, ao contrário do observado no presente estudo, as folhas e os frutos foram os principais drenos.

Por outro lado, se aproximam dos obtidos por Medeiros et al. (2008) que, ao trabalhar com os híbridos Trusty e Orange Flesh, encontraram os valores 9,71 e 6,81 g planta ${ }^{-1}$ de $\mathrm{N}$, respectivamente. Nota-se, portanto, em diversos trabalhos, grande variabilidade no conteúdo de nitrogênio na parte aérea, sinalizando valores, tanto acima quanto abaixo do encontrado 
Tabela 3. Conteúdo* de nitrogênio, fósforo e potássio (g planta-1) em diferentes partes da planta para as cultivares Sancho e Medellín do meloeiro, aos 69 diasapós a semeadura, irrigadas com água de baixa $\left(\mathrm{T}_{1}\right.$ e $\left.\mathrm{T}_{4}\right)$ e alta sal inidade $\left(\mathrm{T}_{5}\right)$

\begin{tabular}{|c|c|c|c|c|}
\hline \multirow{2}{*}{ Tratamentos } & \multicolumn{4}{|c|}{ Parte da planta } \\
\hline & Parte aérea & Folha & Caule & Fruto \\
\hline & \multicolumn{4}{|c|}{ Nitrogênio (g planta-1) } \\
\hline $\mathrm{T}_{1}$ & $9,63 \mathrm{a}$ & $3,41 \mathrm{a}$ & $0,57 \mathrm{a}$ & $5,65 a$ \\
\hline $\mathrm{T}_{4}$ & $9,20 a$ & $3,33 a$ & $0,62 a$ & $5,24 a$ \\
\hline$T_{5}$ & $8,99 a$ & $2,83 a$ & $0,64 a$ & $5,50 a$ \\
\hline Média & 9,27 & 3,19 & 0,61 & 5,46 \\
\hline Sancho & $10,37 a$ & $3,88 \mathrm{a}$ & $0,68 \mathrm{a}$ & $5,81 \mathrm{a}$ \\
\hline Medellín & $8,17 \mathrm{~b}$ & $2,50 \mathrm{~b}$ & $0,54 a$ & $5,12 a$ \\
\hline Média & 9,27 & 3,19 & 0,61 & 5,47 \\
\hline $\mathrm{CV}_{1}(\%)$ & 16,40 & 14,67 & 16,74 & 11,97 \\
\hline \multirow[t]{2}{*}{$\mathrm{CV}_{2}(\%)$} & 23,78 & 15,76 & 18,71 & 16,28 \\
\hline & \multicolumn{4}{|c|}{ Fósforo (g planta ${ }^{-1}$ ) } \\
\hline $\mathrm{T}_{1}$ & $4,98 \mathrm{a}$ & $0,50 a$ & $0,36 \mathrm{a}$ & $4,11 \mathrm{a}$ \\
\hline $\mathrm{T}_{4}$ & $5,13 a$ & $0,75 a$ & $0,40 \mathrm{a}$ & $3,96 a$ \\
\hline$T_{5}$ & $4,41 a$ & $0,55 \mathrm{a}$ & $0,31 \mathrm{a}$ & $3,54 a$ \\
\hline Média & 4,84 & 0,60 & 0,36 & 3,87 \\
\hline Sancho & $5,44 a$ & $0,80 a$ & $0,38 a$ & $4,26 a$ \\
\hline Medellín & $4,23 \mathrm{~b}$ & $0,40 \mathrm{~b}$ & $0,34 a$ & $3,49 a$ \\
\hline Média & 4,84 & 0,60 & 0,36 & 3,88 \\
\hline $\mathrm{CV}_{1}(\%)$ & 27,00 & 27,00 & 20,67 & 15,60 \\
\hline \multirow[t]{2}{*}{$\mathrm{CV}_{2}(\%)$} & 26,34 & 26,34 & 24,95 & 11,42 \\
\hline & \multicolumn{4}{|c|}{ Potássio (g planta ${ }^{-1}$ ) } \\
\hline $\mathrm{T}_{1}$ & $20,28 a$ & $2,45 \mathrm{a}$ & $2,07 a$ & $15,74 a$ \\
\hline $\mathrm{T}_{4}$ & $22,02 a$ & $2,22 a$ & $2,24 a$ & $17,56 a$ \\
\hline$T_{5}$ & $18,05 \mathrm{a}$ & $1,69 a$ & $1,97 a$ & $14,38 \mathrm{a}$ \\
\hline Média & 20,12 & 2,12 & 2,09 & 15,89 \\
\hline Sancho & $21,64 \mathrm{a}$ & $2,47 a$ & $2,36 a$ & $16,80 \mathrm{a}$ \\
\hline Medellín & $18,59 a$ & $1,77 \mathrm{a}$ & $1,82 \mathrm{a}$ & $14,99 \mathrm{a}$ \\
\hline Média & 20,12 & 2,12 & 2,09 & 15,90 \\
\hline $\mathrm{CV}_{1}(\%)$ & 21,07 & 28,17 & 20,99 & 11,98 \\
\hline $\mathrm{CV}_{2}(\%)$ & 23,09 & 19,17 & 15,31 & 13,41 \\
\hline
\end{tabular}

$\mathrm{S}_{1}=0,61 \mathrm{dS} \mathrm{m} \mathrm{m}^{-1}$ e $\mathrm{S}_{2}=4,78 \mathrm{dS} \mathrm{m} \mathrm{m}^{-1} \cdot \mathrm{T}_{1}-\mathrm{S}_{1} \mathrm{~S}_{1} \mathrm{~S}_{2} \mathrm{~S}_{2}, \mathrm{~T}_{2}-\mathrm{S}_{2} \mathrm{~S}_{1} \mathrm{~S}_{2} \mathrm{~S}_{2} \mathrm{~S}_{2} \mathrm{~S}_{2} \mathrm{~S}_{1} \mathrm{~S}_{2}, \mathrm{~T}_{3}-\mathrm{S}_{1} 2$ dias $+\mathrm{S}_{2} 1 \mathrm{dia}$ $\mathrm{T}_{4}-\mathrm{S}_{1} 2$ dias $+\mathrm{S}_{2} 1$ dia, $\mathrm{T}_{5}$ - irrigação com água $\mathrm{S}_{2}$ durante todo 0 ciclo $\mathrm{e} \mathrm{T}_{0}$ - manejo de irrigaçãa com a mistura de $37 \%$ da água $\mathrm{S}_{1}$ e $63 \%$ da água $\mathrm{S}_{2}$

${ }^{*}$ Médias seguidas de letras diferentes na mesma coluna diferem entre si pelo teste de Tukey (P $<0,05)$

no presente estudo. Tal variabilidade pode estar relacionada às diferentes condições de salinidade da água, à tolerância da cultura a salinidade, às características do solo, do clima, do manejo adotado na pesquisa e, ainda, à dose de $\mathrm{N}$ aplicada.

Quanto ao fósforo, não ocorreu diferença significativa entre o fator estratégia de manejo aos 69 DAS em nenhum órgão da planta; já nas cultivares esta diferença foi significativa no conteúdo de fósforo da parte aérea e das folhas, aos 69 DAS, sendo os maiores acúmulos observados na cultivar Sancho, com médias de 5,44 e 4,23 $\mathrm{g}_{\text {planta }}{ }^{-1}$ na parte aérea e 0,8 e 0,4 $\mathrm{g}_{\text {planta }}{ }^{-1}$ na folha para o Sancho e Medellín, respectivamente (Tabela 3).

As quantidades acumuladas de fósforo na parte aérea foram crescentes ao longo do tempo, em todos os tratamentos, notadamente a partir de 42 DAS, cujos frutos são os principais responsáveis por tal comportamento, com predominância da cultivar Sancho sobre a Medellín (Figura 2A a 2F).

Os conteúdos de fósforo nas folhas e no caule apresentaram, em todos os tratamentos, ligeira evolução até os 56 DAS com posterior queda até os 69 DAS (Figura 2A a $2 \mathrm{~F}$ ); já o conteúdo nos frutos se manteve reduzido até os 42

$$
\text { Sancho }
$$

A.
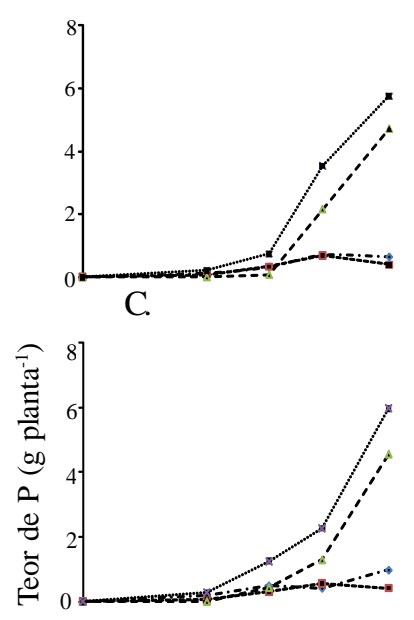

E.

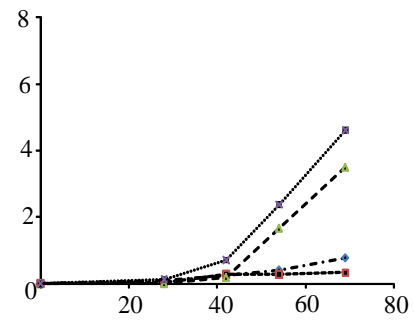

Dias após a semeadura

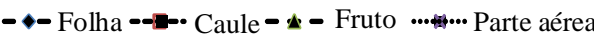

$S_{1}=0,61 \mathrm{dS} \mathrm{m}^{-1} \mathrm{e} \mathrm{S}_{2}=4,78 \mathrm{dS} \mathrm{m}^{-1} \cdot \mathrm{T}_{1}-\mathrm{S}_{1} \mathrm{~S}_{1} \mathrm{~S}_{2} \mathrm{~S}_{2}, \mathrm{~T}_{4}-\mathrm{S}_{1} 2 \mathrm{dias}+\mathrm{S}_{2} 1$ dia e $\mathrm{T}_{5}$ - irrigação com água $S_{2}$ durante todo o ciclo

Figura 2. Acumulação de fósforo da parte aérea, folhas, caule e frutos em função dos dias após a semeadura para as cultivares Sancho e Medellín, nos tratamentos com água boa- $T_{1}(A$ e $B)$ e $T_{4}\left(C\right.$ e D ) e salina $-T_{5}(E e F)$, respectivamente

DAS e, a partir desta data, houve um acentuado acréscimo até o final do ciclo da cultura; este decréscimo no conteúdo de fósforo nas folhas e no caule e o acréscimo nos frutos podem estar relacionados ao aumento da translocação deste elemento daqueles órgãos para os frutos, pois correspondem aos períodos de crescimento e maturação dos mesmos, conforme constatado por Gurgel et al. (2008).

Observa-se ainda que as concentrações de fósforo na parte aérea da cultivar Sancho tenderam a aumentar nos tratamentos menos salinos (Figuras $2 \mathrm{Ae} \mathrm{C}$ ), os quais concentraram 5,75 e 5,97 g planta $^{-1}$, respectivamente, aos 69 DAS; já em condições de alta salinidade (Figura 2E) o acúmulo foi menor, encontrandose o total de 4,61 $\mathrm{g}_{\text {planta-1 }}{ }^{-1}$ fato este não observado na cultivar Medellín na qual se constataram valores semelhantes, sendo 4,21; 4,28 e 4,22 g planta $^{-1}$, nos tratamentos $\mathrm{T}_{1}, \mathrm{~T}_{4}$ e $\mathrm{T}_{5}$, respectivamente (Figuras $2 \mathrm{~B}, \mathrm{D}$ e F, respectivamente).

Não se constatou diferença significativa entre as estratégias de manejo nem entre cultivares sobre os conteúdos de fósforo no fruto, com valores médios obtidos de 4,26 e 3,49 $\mathrm{g} \mathrm{planta}^{-1}$, respectivamente na cv Sancho e na Medellín (Tabela 3). A distribuição do P acumulado pela planta nos seus diferentes órgãos mostrou que o fruto foi o maior contribuinte neste acúmulo, independente do tratamento, cerca de $80 \%$ do total absorvido pela planta; referidos resultados concordam com os 
obtidos por Medeiros et al. (2008) que verificaram, na cultivar Orange Flesh e no híbrido Trusty, acúmulo de $\mathrm{P}$ nos frutos quase duas vezes superior ao acumulado em folhas e caule.

Com relação ao conteúdo de $\mathrm{P}$ encontrado em outras variedades de melão, observa-se variação entre 0,4 - 6 g planta $^{-1}$ conforme descritos por Gurgel et al. (2008) e Medeiros et al. (2008), caso em que o conteúdo de P na parte aérea da planta na presente pesquisa está dentro da média registrada pela literatura.

Em relação ao potássio, a partir de 42 DAS notou-se tendência de aumento no conteúdo de potássio na parte aérea da planta, em todas as estratégias de manejo e cultivares, acompanhando seu crescimento com uma leve superioridade dos tratamentos menos salinos (Figuras 3A, B, C e D) em relação ao mais salino (Figuras E e F). Os maiores conteúdos de potássio foram registrados nos frutos que contribuíram com cerca de $80 \%$ em média da absorção total de K pelas plantas das duas cultivares, seguidos das folhas e caules, não havendo efeito significativo entre tratamentos e cultivares aos 69 DAS em nenhum desses órgãos, com um total acumulado na parte aérea de 21,64 e 18,59 $\mathrm{g}_{\text {planta }}{ }^{-1}$, para as cultivares Sancho e Medellín, respectivamente (Tabela 3). Gurgel et al. (2010b) constataram, na cultivar Orange Flesh, maiores acúmulos de potássio nos fruto, seguidos de caule e folhas o que diverge, em parte, do presente estudo.

\section{Sancho}

A.

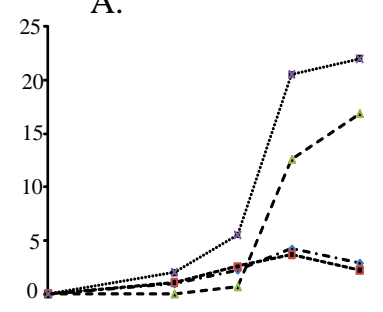

C.

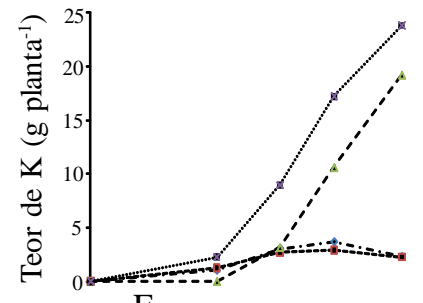

$\mathrm{E}$

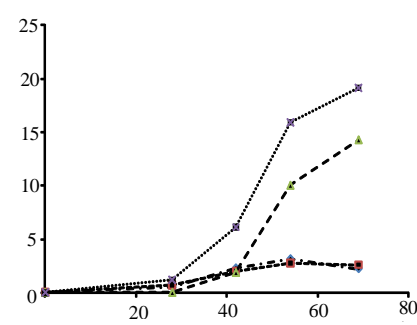

Dias após a semeadura

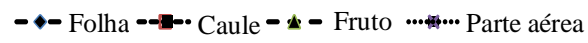

$\mathrm{S}_{1}=0,61 \mathrm{dS} \mathrm{m}^{-1} \mathrm{e} \mathrm{S}_{2}=4,78 \mathrm{dS} \mathrm{m}^{-1} \cdot \mathrm{T}_{1}-\mathrm{S}_{1} \mathrm{~S}_{1} \mathrm{~S}_{2} \mathrm{~S}_{2^{\prime}}, \mathrm{T}_{4}-\mathrm{S}_{1} 2$ dias $+\mathrm{S}_{2} 1$ dia e $\mathrm{T}_{5}$ - irrigação com água $S_{2}$ durante todo o ciclo

Figura 3. Acumulação de potássio da parte aérea, folhas, caule e frutos em função dos dias após a semeadura para as cultivares Sancho e Medellín nos tratamentos com água boa - $T_{1}(A$ e $B)$ e $T_{4}\left(C\right.$ e $D$ ) e salina - $T_{5}(E$ e F ), respectivamente
Ao contrário do observado no presente estudo, Medeiros et al. (2008) registraram, trabalhando com as cultivares Orange Flesh e Trusty, redução significativa no acúmulo de potássio, ao se elevar a CE da água de irrigação, verificando 16,42; 9,81 e 9,36 g planta $^{-1}$ nos níveis de 1,$1 ; 2,5$ e 4,5 $\mathrm{dS} \mathrm{m}^{-1}$, sinal de que a salinidade da água influenciou negativamente na absorção deste nutriente.

Tal divergência é devida, sem dúvida, ao fato da variação genotípica entre as cultivares estudadas quanto a tolerância à salinidade visto que, de acordo com Aktas et al. (2006), o aumento da salinidade da água ou da solução do solo prejudica a absorção radicular de $\mathrm{K}$ e $\mathrm{Ca}$, interferindo nas funções fisiológicas das plantas. Porém, a habilidade dos genótipos de plantas de manter os altos teores de $\mathrm{K}$ e Ca e baixos níveis de $\mathrm{Na}$ dentro do tecido vegetal, é um dos seus mecanismos que contribuem para expressar a maior tolerância à salinidade, ou seja, na maioria dos casos os genótipos tolerantes à salinidade são capazes de manter altas relações K/Na nos tecidos (Zeng et al., 2003).

Percebe-se, em todos os tratamentos, que as concentrações de potássio nas folhas e caule mostraram tendência de acréscimo até os $56 \mathrm{DAS}$, com posterior redução para $69 \mathrm{DAS}$, sendo que no $\mathrm{T}_{1}$ em que se irrigou com água de baixa salinidade até os 42 DAS, o conteúdo de tal nutriente nesses órgãos foi superior ao do tratamento irrigado com água salina $\left(\mathrm{T}_{5}\right)$ (Figura 3); portanto, as duas cultivares tiveram comportamento semelhante quanto ao acúmulo de potássio quando irrigadas com água de baixa e alta salinidade, sinalizando que a salinidade da água não influenciou na absorção deste nutriente, em nenhuma das cultivares.

De modo geral, o acúmulo de cálcio na parte aérea aumentou até o final das avaliações, porém não houve diferença estatística entre os fatores estudados aos 69 DAS, exceto para o conteúdo de Ca nas folhas para o fator cultivar, sendo registrada maior média no conteúdo de Ca para a cv. Sancho (4,55 g planta $\left.^{-1}\right)$ (Tabela 4). Diferente do ocorrido para os acúmulos de N, Pe K, as folhas foram os principais drenos seguidas dos frutos e caule, por se tratar de um nutriente pouco móvel no interior das plantas.

Medeiros et al. (2008) registraram, em estudo com as cultivares Trusty e Orange Flesh, conteúdos de Ca na parte aérea inferiores aos obtidos no presente estudo, que foram de 5,41 e 4,32 $\mathrm{g} \mathrm{planta}^{-1}$, respectivamente. Silva Júnior et al. (2006) obtiveram, na parte aérea total do meloeiro "Pele de Sapo", em média 9,68 g planta $^{-1}$, tendo a rama (folhas e caules) e os frutos contribuído, respectivamente, com 7,41 e 2,27 g planta $^{-1}$.

Com relação ao conteúdo acumulado de magnésio nas folhas aos 69 DAS, não se observou efeito significativo entre tratamentos e, sim, entre cultivares, uma vez que na folha a cv Sancho superou a Medellín, com médias de 1,23 e 0,91 g planta${ }^{1}$, respectivamente (Tabela 4). Aos 69 DAS, em todos os tratamentos os frutos foram os principais responsáveis pelo acúmulo de $\mathrm{Mg}$, representando, em média, $58 \%$ da quantidade de $\mathrm{Mg}$ contida na parte aérea da planta, seguidos das folhas e caules, não ocorrendo diferença significativa entre tratamentos, para nenhum desses órgãos.

Os conteúdos de magnésio encontrados ficaram muito acima dos relatados por Silva Júnior et al. (2006) que observaram, na 
Tabela 4. Conteúdo* de cálcio, magnésio e sódio (g planta ${ }^{-1}$ em diferentes partes da planta para as cultivares Sancho e Medellín aos 69 dias após a semeadura, irrigadas com água de baixa $\left(\mathrm{T}_{1}\right.$ e $\left.\mathrm{T}_{4}\right)$ e alta sal inidade $\left(\mathrm{T}_{5}\right)$

\begin{tabular}{|c|c|c|c|c|}
\hline \multirow{2}{*}{ Tratamentos } & \multicolumn{4}{|c|}{ Parte da planta } \\
\hline & Parte aérea & Folha & Caule & Fruto \\
\hline $\begin{array}{l}\mathrm{T}_{1} \\
\mathrm{~T}_{4} \\
\mathrm{~T}_{5} \\
\text { Média }\end{array}$ & $\begin{array}{l}45,04 a \\
50,91 a \\
42,93 a \\
46,29\end{array}$ & $\begin{array}{l}\text { Cálcio (g } \\
26,00 \text { a } \\
30,98 \text { a } \\
26,77 \text { a } \\
27,92\end{array}$ & $\begin{array}{l}\left.n a^{-1}\right) \\
3,64 \text { a } \\
4,01 \text { a } \\
3,90 \text { a } \\
3,85\end{array}$ & $\begin{array}{l}15,39 a \\
15,91 a \\
12,75 a \\
14,68\end{array}$ \\
\hline $\begin{array}{l}\text { Sancho } \\
\text { Medellín } \\
\text { Média }\end{array}$ & $\begin{array}{l}48,83 a \\
43,76 a \\
46,30\end{array}$ & $\begin{array}{l}28,60 a \\
26,90 a \\
27,75\end{array}$ & $\begin{array}{l}4,55 a \\
3,16 b \\
3,86\end{array}$ & $\begin{array}{l}15,67 a \\
13,69 a \\
14,68\end{array}$ \\
\hline $\begin{array}{l}\mathrm{CV}_{1}(\%) \\
\mathrm{CV}_{2}(\%)\end{array}$ & $\begin{array}{l}17,98 \\
18,91\end{array}$ & $\begin{array}{l}15,17 \\
12,24\end{array}$ & $\begin{array}{l}15,91 \\
14,03\end{array}$ & $\begin{array}{r}9,20 \\
11,73\end{array}$ \\
\hline $\begin{array}{l}\mathrm{T}_{1} \\
\mathrm{~T}_{4} \\
\mathrm{~T}_{5} \\
\text { Média }\end{array}$ & $\begin{array}{l}3,15 a \\
3,82 a \\
3,32 a \\
3,43\end{array}$ & $\begin{array}{c}\text { Magnésio } \\
1,06 \mathrm{a} \\
1,10 \mathrm{a} \\
1,03 \mathrm{a} \\
1,06\end{array}$ & $\begin{array}{l}\operatorname{lanta}^{-1} \text { ) } \\
0,27 \mathrm{a} \\
0,46 \mathrm{a} \\
0,41 \mathrm{a} \\
0,38\end{array}$ & $\begin{array}{l}1,81 \mathrm{a} \\
2,26 \mathrm{a} \\
1,88 \mathrm{a} \\
1,98\end{array}$ \\
\hline $\begin{array}{l}\text { Sancho } \\
\text { Medellín } \\
\text { Média }\end{array}$ & $\begin{array}{l}3,56 \mathrm{a} \\
3,31 \mathrm{a} \\
3,44\end{array}$ & $\begin{array}{l}1,23 \mathrm{a} \\
0,91 \mathrm{~b} \\
1,07 \\
\end{array}$ & $\begin{array}{l}0,37 a \\
0,38 a \\
0,38\end{array}$ & $\begin{array}{l}1,95 a \\
2,01 a \\
1,98\end{array}$ \\
\hline $\begin{array}{l}\mathrm{CV}_{1}(\%) \\
\mathrm{CV}_{2}(\%) \\
\end{array}$ & $\begin{array}{l}23,40 \\
22,43 \\
\end{array}$ & $\begin{array}{l}19,18 \\
15,89 \\
\end{array}$ & $\begin{array}{l}19,92 \\
19,43 \\
\end{array}$ & $\begin{array}{l}11,41 \\
13,45 \\
\end{array}$ \\
\hline $\begin{array}{l}\mathrm{T}_{1} \\
\mathrm{~T}_{4} \\
\mathrm{~T}_{5} \\
\text { Média }\end{array}$ & $\begin{array}{l}2,75 a \\
3,23 a \\
3,70 a \\
3,23\end{array}$ & $\begin{array}{l}\text { Sódio }(\mathrm{g} \\
0,53 \mathrm{a} \\
0,53 \mathrm{a} \\
0,68 \mathrm{a} \\
0,58\end{array}$ & $\begin{array}{l}\left.n+a^{-1}\right) \\
0,63 \mathrm{~b} \\
0,72 \mathrm{~b} \\
1,08 \mathrm{a} \\
0,81\end{array}$ & $\begin{array}{l}1,58 \mathrm{a} \\
1,97 \mathrm{a} \\
1,93 \mathrm{a} \\
1,83 \\
\end{array}$ \\
\hline $\begin{array}{l}\text { Sancho } \\
\text { Medellín } \\
\text { Média }\end{array}$ & $\begin{array}{l}3,43 a \\
3,02 a \\
3,23\end{array}$ & $\begin{array}{l}0,66 a \\
0,50 a \\
0,58\end{array}$ & $\begin{array}{l}0,96 a \\
0,67 b \\
0,82\end{array}$ & $\begin{array}{l}1,80 \mathrm{a} \\
1,85 \mathrm{a} \\
1,83\end{array}$ \\
\hline $\begin{array}{l}\mathrm{CV}_{1}(\%) \\
\mathrm{CV}_{2}(\%)\end{array}$ & $\begin{array}{l}21,52 \\
24,45\end{array}$ & $\begin{array}{l}25,60 \\
23,64\end{array}$ & $\begin{array}{l}14,69 \\
13,43\end{array}$ & $\begin{array}{l}12,65 \\
13,90\end{array}$ \\
\hline
\end{tabular}

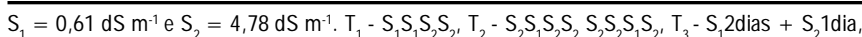
$\mathrm{T}_{4}-\mathrm{S}_{1} 2$ dias $+\mathrm{S}_{2} 1$ dia, $\mathrm{T}_{5}$ - irrigação com água $\mathrm{S}_{2}$ durante todo 0 ciclo $\mathrm{e}_{0}$ - manejo de irrigação com a mistura de $37 \%$ da água $\mathrm{S}_{1}$ e $63 \%$ da água $\mathrm{S}_{2}$

*Médias seguidas de letras diferentes na mesma coluna diferem entre si pelo teste de Tukey ( $P$ $<0,05)$

parte aérea do melão Pele de Sapo, o total de $0,97 \mathrm{~g} \mathrm{planta}^{-1} \mathrm{e}$ próximos aos encontrados por Medeiros et al. (2008), que constataram valores entre 1 a 3 g planta $^{-1}$.

Aos 69 DAS constata-se efeito significativo no conteúdo de sódio apenas no caule das plantas entre tratamentos e cultivares (Tabela 4). $\mathrm{O} \mathrm{T}_{5}$ foi superior aos $\mathrm{T}_{1}$ e $\mathrm{T}_{4}$, que não se diferenciaram entre si a 0,05 de probabilidade; já entre cultivares a Sancho acumulou mais sódio no caule do que a Medellín (Tabela 4); percebe-se, portanto, que a diferença observada na absorção de sódio no caule entre tratamentos pode estar diretamente ligada à alta concentração desse íon na água salina $\left(\mathrm{S}_{2}\right)$ (Tabela 1). Gurgel et al. (2010b) também constataram, nas cultivares Orange Flesh e Goldex, maiores acúmulos de sódio em condições de alta salinidade.

A habilidade dos genótipos de excluir $\mathrm{Na}$ da raiz durante o crescimento, é um mecanismo de adaptação importante ao meio salino, ou seja, genótipos mais tolerantes à salinidade tendem a acumular menor quantidade de $\mathrm{Na}$ no tecido vegetal, a exemplo da cultivar Medellín, no presente estudo, contribuindo para aumentar a relação $\mathrm{K} / \mathrm{Na}$ no tecido vegetal das folhas e caule e expressar a alta tolerância aos sais (Yoshida, 2002).
Com base nesta constatação infere-se que a cultivar Medellín manteve uma relação maior K/Na $(2,71)$ do que a Sancho $(2,45)$, o que pode indicar uma maior tolerância à salinidade.

Ao final do ciclo da cultura não houve efeito significativo entre tratamentos e cultivares no acúmulo de sódio nas folhas; no entanto, $\mathrm{o} \mathrm{T}_{5}$ tendeu a acumular mais este elemento assim como a cultivar Sancho, que acumulou $0,66 \mathrm{~g}_{\text {planta }}{ }^{-1}$ contra 0,50 g planta $^{-1}$ da Medellín (Tabela 4).

O conteúdo de sódio na parte aérea da cultivar Sancho no tratamento mais salino $\left(\mathrm{T}_{5}\right)$ foi superior aos menos salinos $\left(\mathrm{T}_{1} \mathrm{e} \mathrm{T}_{4}\right)$, com médias, nesta sequência de 4,02; 2,88 e 3,01 g planta $^{-1}$ superando, inclusive, o conteúdo de magnésio (Tabela 3); comportamento semelhante também foi verificado para a cultivar Medellín porém em menor concentração, com médias para os tratamentos $\mathrm{T}_{5}, \mathrm{~T}_{4} \mathrm{e} \mathrm{T}_{1}$ de 3,39; 3,06 e 2,63 $\mathrm{g} \mathrm{planta}^{-1}$ de sódio, respectivamente.

No final do ciclo, aos 69 DAS, não ocorreu efeito significativo entre estratégia de manejo e cultivares para o teor de ferro da parte aérea (Tabela 5). Conforme verificado na parte

Tabela 5. Conteúdo* de ferro, cobre, zinco e manganês ( $m g$ planta ${ }^{-1}$ ) em diferentes partes da planta nas cultivares Sancho e M edellín aos 69 dias após a semeadura, irrigadas com água de baixa $\left(\mathrm{T}_{1}\right.$ e $\left.\mathrm{T}_{4}\right)$ e al ta sal inidade $\left(\mathrm{T}_{5}\right)$

\begin{tabular}{|c|c|c|c|c|}
\hline \multirow{2}{*}{ Tratamentos } & \multicolumn{4}{|c|}{ Parte da planta } \\
\hline & Parte aérea & Folha & Caule & Fruto \\
\hline & \multicolumn{4}{|c|}{ Ferro (mg planta ${ }^{-1}$ ) } \\
\hline $\mathrm{T}_{1}$ & $41,14 a$ & $19,96 a$ & $3,56 a$ & $17,61 \mathrm{a}$ \\
\hline $\mathrm{T}_{4}$ & $50,35 a$ & $22,37 \mathrm{a}$ & $4,01 \mathrm{a}$ & $23,97 \mathrm{a}$ \\
\hline$T_{5}$ & $41,53 \mathrm{a}$ & $16,80 \mathrm{a}$ & $4,03 \mathrm{a}$ & $20,89 a$ \\
\hline Média & 44,34 & 19,71 & 3,87 & 20,82 \\
\hline Sancho & $45,26 a$ & $20,70 a$ & $4,47 a$ & $20,09 a$ \\
\hline Medellín & $43,43 a$ & $18,59 \mathrm{a}$ & $3,26 a$ & $21,56 a$ \\
\hline \multirow[t]{2}{*}{ Média } & 44,35 & 19,65 & 3,87 & 20,83 \\
\hline & \multicolumn{4}{|c|}{ Cobre (mg planta ${ }^{-1}$ ) } \\
\hline $\mathrm{T}_{1}$ & $6,76 \mathrm{a}$ & $0,97 a$ & $0,33 a$ & $5,45 a$ \\
\hline $\mathrm{T}_{4}$ & 7,18 a & $0,88 a$ & $0,49 a$ & $5,81 \mathrm{a}$ \\
\hline $\mathrm{T}_{5}$ & $5,35 a$ & $0,68 \mathrm{a}$ & $0,38 \mathrm{a}$ & $4,29 a$ \\
\hline Média & 6,43 & 0,84 & 0,40 & 5,18 \\
\hline Sancho & $6,81 \mathrm{a}$ & $0,88 a$ & $0,44 a$ & $5,48 \mathrm{a}$ \\
\hline Medellín & $6,05 a$ & $0,80 a$ & $0,36 a$ & $4,88 \mathrm{a}$ \\
\hline \multirow[t]{2}{*}{ Média } & 6,43 & 0,84 & 0,40 & 5,18 \\
\hline & \multicolumn{4}{|c|}{ Znco (mg planta ${ }^{-1}$ ) } \\
\hline $\mathrm{T}_{1}$ & $49,51 \mathrm{a}$ & $7,45 a$ & $3,89 a$ & $38,17 \mathrm{a}$ \\
\hline $\mathrm{T}_{4}$ & $57,64 a$ & $6,97 \mathrm{a}$ & $4,50 a$ & $46,16 a$ \\
\hline$T_{5}$ & $49,41 \mathrm{a}$ & $6,12 \mathrm{a}$ & $4,47 a$ & $38,81 \mathrm{a}$ \\
\hline Média & 52,19 & 6,85 & 4,29 & 41,05 \\
\hline Sancho & $55,28 a$ & $7,91 \mathrm{a}$ & $4,86 a$ & $42,52 \mathrm{a}$ \\
\hline Medellín & $49,09 a$ & $5,79 b$ & $3,72 a$ & $39,58 \mathrm{a}$ \\
\hline \multirow[t]{2}{*}{ Média } & 52,19 & 6,85 & 4,29 & 41,05 \\
\hline & \multicolumn{4}{|c|}{ Manganês (mg planta ${ }^{-1}$ ) } \\
\hline $\mathrm{T}_{1}$ & $51,58 \mathrm{a}$ & $6,31 b$ & $3,61 \mathrm{a}$ & $41,66 \mathrm{a}$ \\
\hline $\mathrm{T}_{4}$ & $66,48 \mathrm{a}$ & $11,59 a$ & $3,46 a$ & $51,42 a$ \\
\hline$T_{5}$ & $57,36 \mathrm{a}$ & 9,93ab & $4,41 a$ & $43,02 \mathrm{a}$ \\
\hline Média & 58,47 & 9,28 & 3,83 & 45,37 \\
\hline Sancho & $60,70 a$ & $9,90 \mathrm{a}$ & $4,61 \mathrm{a}$ & $46,18 \mathrm{a}$ \\
\hline Medellín & $56,26 a$ & $8,66 \mathrm{a}$ & $3,04 \mathrm{~b}$ & $44,55 a$ \\
\hline Média & 58,48 & 9,28 & 3,83 & 45,37 \\
\hline
\end{tabular}

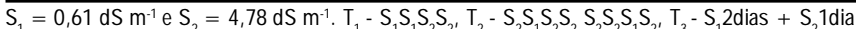
$\mathrm{T}_{4}-\mathrm{S}_{1} 2$ dias $+\mathrm{S}_{2} 1$ dia, $T_{5}$ - irrigação com água $\mathrm{S}_{2}$ durante todo 0 ciclo $\mathrm{e} \mathrm{T}_{0}$ - manejo de irrigação com a mistura de $37 \%$ da água $\mathrm{S}_{1}$ e $63 \%$ da água $\mathrm{S}_{2}$

Médias seguidas de letras diferentes na mesma coluna diferem entre si pelo teste de Tukey ( $P$ $<0,05$ ) 
aérea, o total acumulado de ferro aos 69 DAS, tanto entre manejo de água e cultivares nas folhas, caules e frutos (Tabela 5). De igual forma, o teor de cobre no tecido vegetal não diferiu estatisticamente entre os fatores estudados sendo observada aos 69 DAS, pequena diferença da Sancho em relação à Medellín (Tabela 5).

Aos 69 DAS nota-se efeito não significativo entre tratamentos e significativo entre cultivares (folhas) para a variável teor de zinco, sendo a cultivar Sancho superior à Medellín em aproximadamente $25 \%$ do total absorvido (Tabela 4). No caule das duas cultivares, independente do fator estratégia de manejo, a acumulação de zinco teve comportamento semelhante (Tabela 5).

Para o teor de manganês não se constatou diferença significativa nos fatores estudados nos frutos (Tabela 4); entretanto, ao longo do tempo todos os tratamentos foram responsáveis pela maior presença desse nutriente. Nos tratamentos menos salino, as plantas da cultivar Sancho tenderam a acumular mais manganês na parte aérea do que a Medellín; já em condições de alta salinidade, o conteúdo foi similar nas duas cultivares.

Com relação ao comportamento do acúmulo de manganês nas folhas nota-se que o acúmulo foi crescente até os 56 DAS, reduzindo até a última avaliação; já no total acumulado observase efeito significativo entre tratamentos; $\mathrm{o}_{4}$ foi superior aos demais acumulando, em média, $11,59 \mathrm{mg}$ planta $^{-1}$, sendo estatisticamente igual ao $\mathrm{T}_{5}$ e diferente do $\mathrm{T}_{1 ;}$ este, por sua vez, não diferiu estatisticamente do $\mathrm{T}_{5}$ (Tabela 4 ).

A ordem decrescente de extração dos nutrientes dos tratamentos $\mathrm{T}_{1}$ e $\mathrm{T}_{4}$ na cv Sancho e de todos os tratamentos na cultivar Medellín, foi $\mathrm{Ca}>\mathrm{K}>\mathrm{N}>\mathrm{P}>\mathrm{Mg}>\mathrm{Na}>\mathrm{Zn}>\mathrm{Mn}>\mathrm{Fe}$ $>\mathrm{Cu}$ já no $\mathrm{T}_{5}$ da cv Sancho foi $\mathrm{Ca}>\mathrm{K}>\mathrm{N}>\mathrm{P}>\mathrm{Na}>\mathrm{Mg}>\mathrm{Zn}$ $>\mathrm{Mn}>\mathrm{Fe}>\mathrm{Cu}$, sendo igual ao anterior, exceto o conteúdo de $\mathrm{Na}$, que superou o de $\mathrm{Mg}$.

\section{CONClusÕes}

1. O acúmulo de fitomassa seca total na parte aérea da cultivar Sancho superou a Medelín em todas as estratégias de manejo da salinidade e os nutrientes mais exigidos pelas duas cultivares, foram o $\mathrm{Ca}, \mathrm{K}$ e N .

2. Nos frutos ocorrem os maiores acúmulos de matéria seca, chegando a $71,79 \%$ na cultivar Sancho e $80,23 \%$ na cultivar Medellín, aos 69 DAS, em alta salinidade.

3. Em condições de salinidade, a cultivar Medellín manteve a maior relação K/Na no caule quando comparada com a cv. Sancho e, portanto, expressou maior capacidade de adaptação ao meio salino.

\section{LITERATURA CITADA}

Aktas, H.; Abak, K.; Cakmak, I. Genotypic variation in the response of pepper to salinity. Scientiae Horticulturae, v.110, p.260-266, 2009.
Allen, R. G.; Pereira, L. S.; Raes, D.; Smith, M. Crop evapotranspiration: Guidelines for computing crop water requirements. Rome: FAO, 1998. 300p. Irrigation and Drainage Paper, 56

Aragão, C. A.; Santos, J. S.; Queiroz, S. O. P.; França, B. Avaliação de cultivares de melão sob condições de estresse salino. Revista Caatinga, v.22, p.161-169, 2009.

Dias, N. da S.; Duarte, S. N.; Teles Filho, J. F.; Yoshinaga, R. T. Salinização do solo por aplicação de fertilizantes em ambiente protegido. Irriga, v.12, p.135-143, 2007.

Dias, N. S.; Lira, R. B.; Brito, B. L.; Sousa Neto, O. N.; Ferreira Neto, M.; Oliveira, A. M. Produção de melão rendilhado em sistema hidropônico com rejeito da dessalinização de água em solução nutritiva. Revista Brasileira de Engenharia Agrícola eAmbiental, v.14, p.755-761, 2010.

EMBRAPA - Empresa Brasileira de Pesquisa Agropecuária. Manual de métodos de análises de solo. 2.ed. Rio de Janeiro: Ministério da Agricultura e do Abastecimento, 1997. 212p.

EMBRAPA - Empresa Brasileira de Pesquisa Agropecuária. Manual de análises químicas de solos, plantas e fertilizantes. Brasília: EMBRAPA, 1999.370p.

Gurgel, M. T.; Gheyi, H. R.; Oliveira, F. H. T. de. Acúmulo de matéria seca e nutrientes em meloeiro produzido sob estresse salino e doses de potássio. Revista Ciência Agronômica, v.41, p.18-28, 2010a.

Gurgel, M. T.; Gheyi, H. R.; Oliveira, F. H. T. de; Fernandes, P. D.; Silva, F. V. Nutrição de cultivares de meloeiro irrigadas com águas de baixa e alta salinidade. Revista Caatinga, v.21, p.36-43, 2008.

Gurgel, M. T.; Uyeda, C. A.; Gheyi, H. R.; Oliveira, F. H. T. de; Fernandes, P. D.; Silva, F. V. Crescimento de meloeiro sob estresse salino e doses de potássio. Revista Brasileira de Engenharia Agrícola e Ambiental, v.14, p.1-3-10, 2010 b.

IBGE - Instituto Brasileiro De Geografia e Estatística. SIDRA 97: Sistema IBGE de recuperação automática. Rio de Janeiro, 2010. <http://www.sidra.ibge.gov.br/bda/agric>. 6 Ago. 2010.

Medeiros, J. F. de; Duarte, S. R.; Fernandes, P. D.; Dias, N. da S.; Gheyi, H. R. Crescimento e acúmulo de N, P e K pelo meloeiro irrigado com água salina. Horticultura Brasileira, v.26, p.452-457, 2008.

Porto Filho, F. de Q.; Medeiros, J. F. de; Sousa Neto, E. R. de; Gheyi, H. R.; Matos, J. de A. Viabilidade da irrigação do meloeiro com águas salinas em diferentes fases fenológicas. Ciência Rural, v.36, p.453-459, 2006.

Santos, A. N.; Soares, T. M.; Silva, E. F. F.; Silva, D. J. R.; Montenegro, A. A. A. Cultivo hidropônico de alface com água salobra subterrânea e rejeito da dessalinização em Ibimirim, PE. Revista Brasileira de Engenharia Agrícola e Ambiental, v.14, p.961-969, 2010.

Silva Júnior, M. J.; Medeiros, J. F. de; Oliveira, F. H. T. de; Dutra, I. Acúmulo de matéria seca e absorção de nutrientes pelo meloeiro "Pele-de-Sapo". Revista Brasileira de Engenharia Agrícola e Ambiental, v.10, p.364-368, 2006. 
Soares, T. M.; Silva, I. J. O.; Duarte, S. N.; Silva, E. F .F. Destinação de águas residuárias provenientes do processo de dessalinização por osmose reversa. Revista Brasileira de Engenharia Agrícola e Ambiental, v.10, p.730-737, 2006.

Souza, D. L. R. Estudo das Vantagens competitivas do melão no Ceará. Fortaleza: Instituto Agropolos do Ceará, 1.ed., 2006.56p.
Taiz, L.; Zeiger, E. Plant physiology. Sunderland: Sinauer Associates, 5.ed. 2010. 782p.

Yoshida, K. Plant biotechnology genetic engineering to enhance plant salt tolerance. Jounal Bioscience Bioengineering, v.94, p.585-590, 2002.

Zeng, L.; Poss, J.; Wilson, C.; Draz, A. S. E.; Grieve, C. M. Evaluation of salt tolerance in rice genotypes by physiological characters. Euphytica, v.129, p.281-292, 2003. 